\title{
Radiological progression of rheumatoid arthritis in renal transplant recipients
}

\author{
A LAMMINEN, T PETTERSSON, L LAASONEN, B KUHLBÄCK, \\ AND J EDGREN \\ From the Fourth Department of Medicine, Helsinki University Central Hospital, Unioninkatu 38, SF-00170 \\ Helsinki 17, Finland
}

SUMMARY Radiological progression of rheumatoid arthritis (RA) was evaluated retrospectively in eight patients with amyloidosis secondary to classical or definite RA and successful renal transplantation. Wrist joints, metacarpophalangeal, proximal interphalangeal, and metatarsophalangeal joints were graded on a scale from 0 to 5 . The annual progression rate was calculated separately for the time before and after transplantation. A slight acceleration of the progression was observed after transplantation and is assumed to be due to activation of the rheumatoid disease when the azotaemia was corrected.

Key words: amyloidosis, azotaemia.

Renal transplantation has been performed on patients with amyloidosis secondary to rheumatoid arthritis (RA) at the Helsinki University Central Hospital since 1973. In patients with RA and renal transplants inflammatory activity in the joints is influenced by a number of factors, including the degree of azotaemia and the immunosuppressive drugs given. In the literature we have found no data on the behaviour of rheumatoid disease in patients who have undergone renal transplantation. The present study examines retrospectively the joint radiographs of eight patients with $\mathrm{RA}$ and a successful renal transplantation.

\section{Patients and methods}

Between 1973 and 1982 a total of 1111 renal transplantations were performed at Helsinki University Central Hospital. Renal amyloidosis was the cause of renal failure in 48 patients, 31 of whom had classical or definite RA as their primary disorder. Eight of the patients with a successful transplantation (graft survival exceeding six months) had an adequate radiological follow-up of RA. As immunosuppressive treatment glucocorticoids and azathioprine were used. The initial dose of methylprednisolone was 68-100 $\mathrm{mg}$ per day; thereafter the dose was gradually reduced. Twelve months after the trans- plantation the dose was 4-20 mg per day. All patients entered an alternative day schedule within six months. The azathioprine dose was $2 \cdot 0-2.5 \mathrm{mg}$ per $\mathrm{kg}$ per day. Rejections were treated with intravenously administered methylprednisolone pulses $0.5-1.0 \mathrm{~g}$ per day (total dose $2-5 \mathrm{~g}$ ). The clinical characteristics of the patients are shown in Table 1.

Radiographs of the patients were available for periods of 7 to 11 years before transplantation and for three to four years after the operation. Standard films of the hands and feet were obtained on average four times before and three times after transplantation. Rheumatoid involvement of the four lateral metatarsophalangeal (MTP 2-5), metacarpophalangeal (MCP 2-5) and proximal interphalangeal (PIP 2-5) joints and the wrist (W) joints was graded from standard reference radiographs according to the scoring system of Larsen et al. ${ }^{1}$ All radiographs were evaluated by the same observer in chronological order without knowledge of clinical or laboratory findings. According to Larsen et al.'s grading system grade 0 represents the normal status of the joint; grade 1 is defined by the presence of any of the following changes-periarticular soft tissue swelling, periarticular osteoporosis, or slight joint space narrowing; grades 2 to 4 represent increasing degrees of definite erosion; and grade 5 describes severe mutilating changes with disappearance of the original articular surfaces. 
Table 1 Clinical data on eight patients with amyloidosis secondary to rheumatoid arthritis $(R A)$ and successful renal transplantation

\begin{tabular}{|c|c|c|c|c|c|c|c|}
\hline \multirow[t]{2}{*}{$\begin{array}{l}\text { Patient } \\
\text { no. }\end{array}$} & \multirow[t]{2}{*}{ Sex } & \multirow[t]{2}{*}{$\begin{array}{l}\text { Age at } \\
\text { transplantation } \\
\text { (years) }\end{array}$} & \multirow[t]{2}{*}{$\begin{array}{l}\text { Rheumatoid } \\
\text { factor }\end{array}$} & \multicolumn{2}{|c|}{$\begin{array}{l}\text { Duration of } R A \\
\text { and azotaemia* before } \\
\text { transplantation (years) }\end{array}$} & \multirow[t]{2}{*}{$\begin{array}{l}\text { Preserved } \\
\text { graft function } \dagger \\
\text { (years) }\end{array}$} & \multirow[t]{2}{*}{$\begin{array}{l}\text { Patient } \\
\text { follow-up }\end{array}$} \\
\hline & & & & $R A$ & Azotaemia & & \\
\hline 1 & $\mathbf{F}$ & 47 & + & 16 & 3 & Over 3 & Alive \\
\hline 2 & $\mathbf{F}$ & 48 & + & 24 & 2 & 1.5 & Death from septicaemia \\
\hline 3 & $\mathbf{F}$ & 49 & + & 16 & 0.5 & Over 5 & Alive \\
\hline 4 & $\mathbf{F}$ & 52 & + & 32 & 0.5 & 2 & Death from uraemia \\
\hline 5 & $\mathrm{~F}$ & 56 & + & 17 & 1 & Over 3 & Alive \\
\hline 6 & $\mathbf{M}$ & 34 & + & 13 & 0.5 & 1.5 & Alive on dialysis \\
\hline 7 & $\mathbf{M}$ & 27 & - & 7 & 2 & 2 & Alive on dialysis \\
\hline 8 & $\mathbf{M}$ & 28 & - & 8 & 2 & Over 4 & Alive \\
\hline
\end{tabular}

${ }^{*}$ S-creatinine over $400 \mu \mathrm{mol} / \mathrm{l}$.

†S-creatinine under $200 \mu \mathrm{mol} / \mathrm{l}$.

Mean grade values were calculated for each group of joints at each $x$-ray examination. The groups included the corresponding joints of the right and the left sides. The slope value $S$ indicates how many grades the joints had worsened in one year. ${ }^{2}$ Mean S values were calculated separately for the pretransplant and post-transplant periods in each joint group. Wilcoxon's test for paired differences was used to analyse the changes.

\section{Results}

Fig. 1 shows the average radiological progression of $\stackrel{0}{0}$ RA before and after renal transplantation in each of

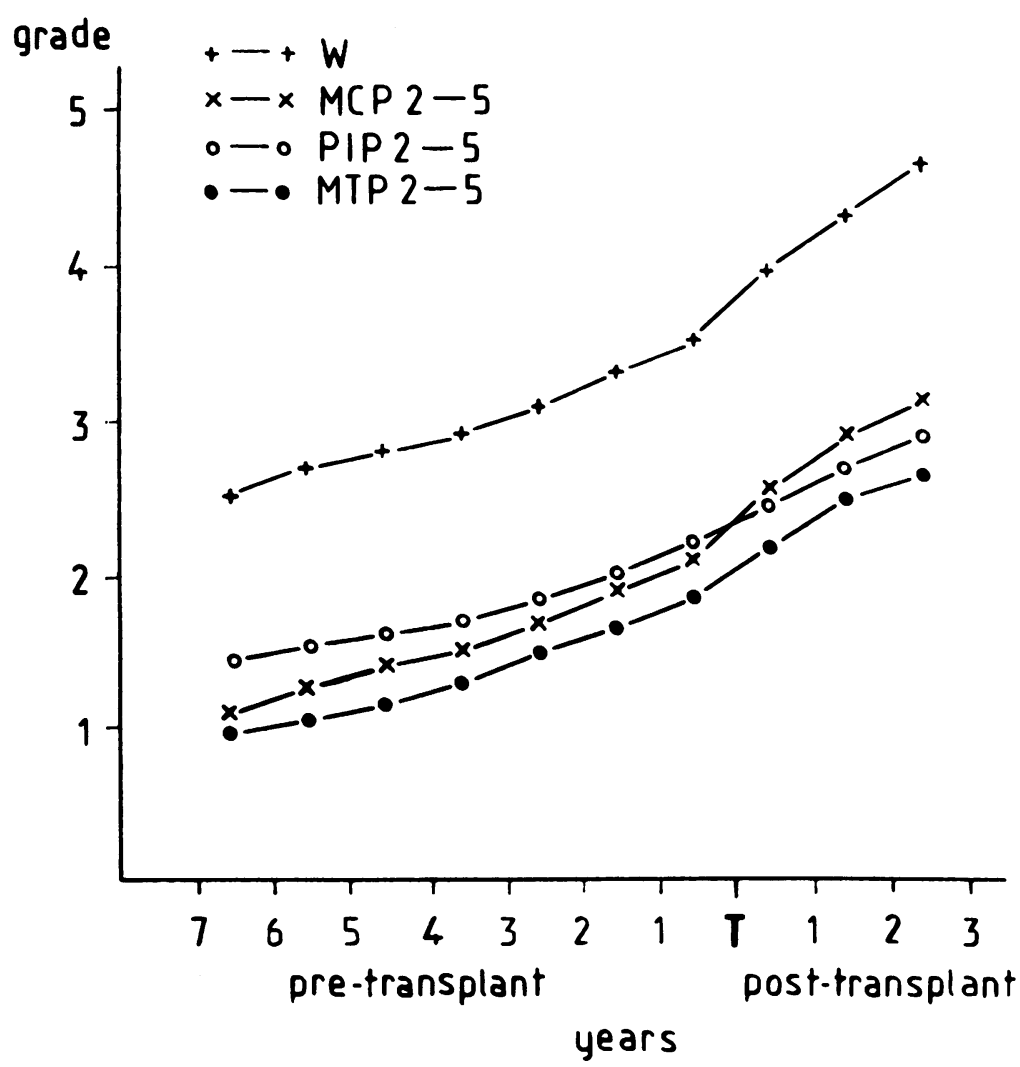

Fig. 1. Average progression of rheumatoid arthritis before and 8 after renal transplantation; mean Larsen grade values in the wrists (W) and the four lateral metacarpophalangeal (MCP 2-5), proximal interphalangeal (PIP 2-5), and metatarsophalangeal (MTP 2-5) joints. ( $\mathrm{T}=$ time of transplantation). 
Table 2 Mean slope values for selected joint groups in renal allograft recipients with classical or definite rheumatoid arthritis $(n=8)$

\begin{tabular}{llllll}
\hline Joints & \multicolumn{2}{l}{$\begin{array}{l}\text { Before } \\
\text { transplantation }\end{array}$} & & \multicolumn{2}{l}{$\begin{array}{l}\text { After } \\
\text { transplantation }\end{array}$} \\
\cline { 2 - 3 } \cline { 5 - 6 } & Mean & SEM & & Mean & SEM \\
\hline W & 0.15 & 0.04 & & 0.39 & 0.14 \\
MCP 2-5 & 0.15 & 0.04 & & 0.24 & 0.06 \\
PIP 2-5 & $0 \cdot 14$ & 0.03 & & $0 \cdot 21$ & 0.04 \\
MTP 2-5 & 0.13 & 0.04 & & 0.19 & 0.02 \\
\hline
\end{tabular}

SEM $=$ standard error of the mean.

the four joint groups (W, MCP 2-5, PIP 2-5, MTP $2-5$ ). In the wrists, MCP 2-5 joints, and MTP 2-5 joints the radiological course of the disease was more progressive after than before kidney transplantation. In PIP 2-5 joints the change in rate of progression was less apparent.

The average annual disease progression in the selected joint groups is shown by the mean slope values in Table 2 . The changes in $S$ values are indicative of a trend of slightly increasing radiological progression after transplantation, though the trend is not statistically significant. The greatest average post-transplant change was seen in the wrists, but these joints also had the highest standard error values. The most uniform course was in MTP 2-5 and in PIP 2-5 joints, both of which also showed increasing radiological involvement.

Active synovitis was not seen in any of the patients during the azotaemic phase before transplantation. Clinical signs and symptoms of active synovitis appeared in two patients (Nos. 5 and 8) during the follow-up after transplantation.

\section{Discussion}

Increasing evidence shows that immunological reactions play an important role in the pathogenesis and progression of RA. Many clinicians share the impression that the activity of RA decreases as amyloidosis and renal failure develop. Furthermore, uraemia is known to have immunosuppressive effects, ${ }^{3-5}$ and immunosuppressive drugs are used after kidney transplantation. Thus suppression of rheumatoid disease activity would be expected in both the azotaemic phase and during the post-transplantation period. A corresponding phenomenon has been seen in patients with systemic lupus erythematosus and end-stage renal disease. They usually have a low incidence of non-renal lupus activity, both clinically and serologically, and remission seems to extend into the period of dialysis and transplantation. ${ }^{6}$ However, RA seems to follow a somewhat different pattern.

The present study shows a slightly accelerated progression of the radiological changes after successful renal transplantation. The duration of azotaemia was relatively short in these patients (between 0.5 and 3 years), and therefore the possible inhibitory effect of azotaemia could not be evaluated separately. Clinically the disease seemed rather inactive during the azotaemic phase prior to transplantation in all patients. The fact that only two patients developed signs of active synovitis after transplantation may be due to the effect of immunosuppressive treatment on the symptoms of RA, while the disease still progressed silently. ${ }^{7}$ Moreover the usual laboratory indices of inflammation are inconclusive in azotaemia.

We considered that the decrease of bone mineral content induced by corticosteroids had no significant influence on the degree of joint erosions in these patients with longstanding RA.

Quantitative assessment of the radiological progression of RA is impossible without a grading system; several different methods have been proposed. ${ }^{8-10}$ We chose the scoring system introduced by Larsen et al. ${ }^{1}$ which has been found useful and practical. ${ }^{71112}$ Although de Carvalho ${ }^{13}$ criticised the method for underestimating the progression of RA when the observation period was short, we did not find this feature disadvantageous. The progression of the radiological involvement could best be demonstrated in the wrist joints, but a similar tendency was observed in all the other joint groups studied, namely, the MCP 2-5, PIP 2-5, and MTP 2-5 joints. If the patient group had been larger the slope values might have been statistically significant. Many patients had advanced disease at the time of transplantation, and many joints had already reached the maximum score; thus there could be no further impairment. In the MCP, PIP, and MTP groups there were many normal joints, a fact which may explain why the wrist joints seemed to be the most sensitive indicator of progression.

Our study offers insight into the behaviour of RA in recipients of renal allografts and points to a slight increase in disease activity after a successful transplantation. Prospective studies on larger series of patients might further elucidate the radiological and immunological phenomena seen in this relatively new subgroup of RA patients.

Gratitude is expressed to our former chief, Professcr Otto Wegelius, MD. 


\section{References}

1 Larsen A, Dale K, Eek M. Radiographic evaluation of rheumatoid arthritis and related conditions by standard reference films. Acta Radiol (Diagn) (Stockh) 1977; 18: 481-91.

2 Larsen A. The value of individual joints for radiologic assessment of rheumatoid arthritis. Scand J Rheumatol 1976; 5: 119-23.

3 Lawrence H S. Uraemia-nature's immunosuppressive device. Ann Intern Med 1965; 62: 166-70.

4 Birkeland S A. Uremia as a state of immune deficiency. Scand J Immunol 1976; 5: 107-15.

5 Häyry $P$, von Willebrand $E$; Taskinen $E$, Höckerstedt $K$, Ahonen J, Eklund B. Is uremia suppressive in renal transplantation? Transplantation 1982; 34: 268-72.

6 Coplon N S, Diskin C J, Petersen J, Swenson R S. The long-term clinical course of systemic lupus erythematosus in end-stage renal disease. $N$ Engl $J$ Med 1983: 308: 186-90.
7 Scott D L, Grindulis K A, Struthers G R, Coulton B L, Popert A J, Bacon P A. Progression of radiological changes in rheumatoid arthritis. Ann Rheum Dis 1984; 43: 8-17.

8 Kellgren J H, Lawrence J S. Radiological assessment of rheumatoid arthritis. Ann Rheum Dis 1957; 16: 485-93.

9 Berens D, Lin R. Roentgen diagnosis of rheumatoid arthritis Springfield: Thomas, 1969.

10 Trentham D E, Masi A T. Carpo-metacarpal ratio, a new quantitative measure of radiologic progression of wrist involvement in rheumatoid arthritis. Arthritis Rheum 1976; 19: 939-44. on

11 Luukkainen $\mathrm{R}$, Isomäki $\mathrm{H}$, Kajander A. Effect of gold $\overrightarrow{0}$ treatment on the progression of erosions in RA patients. Scand J Rheumatol 1977: 6: 123-7.

12 de Carvalho A, Graudal B, Jørgensen B. Radiologic evaluation of the progression of rheumatoid arthritis. Acta Radiol (Diagn) (Stockh) 1980; 21: 115-21.

13 de Carvalho A. Discriminative power of Larsen's grading system for assessing the course of rheumatoid arthritis. Acta + Radiol (Diagn) (Stockh) 1981; 22: 77-80. 